\title{
Quartz. Rocks. Education. The crystallographic contributions of Elizabeth A. Wood
}

\author{
Margaret E. Schott \\ Department of Chemistry, Northwestern University, 2145 Sheridan Road, Evanston, Illinois, USA \\ m-schott@northwestern.edu
}

It was during the war years (1943) that Bell Telephone Laboratories hired their first woman scientist, Dr. Elizabeth J. Armstrong (later Wood). Betty, as she was known, would spend the next 24 years working in physical research at the company's Murray Hill, NJ location. Her major contributions were in the areas of mineralogy, crystallography, ferroelectricity, and superconducting materials, as well as in science education.

In addition to teaching crystallography to colleagues at Bell Labs, including a future Nobel Prize winner [1], her investigations of the structure of quartz and its surface layers contributed to the development of single crystal oscillators being used for radio frequency tuning during WWII.

Thanks to her innate leadership ability and a talent for writing and speaking clearly, Wood was instrumental in setting up the American Crystallographic Association [2] as well as spearheading new programs for physics education.

Wood was the author of numerous influential articles, patents, books and manuals, for both technical and lay readers, including "Crystals and Light" and "Science from Your Airplane Window." She also traveled widely, giving talks at conferences and in support of the rightful role women in science. Betty obtained her undergraduate and graduate degrees in geology from Barnard and Bryn Mawr Colleges, respectively. Her fruitful lifetime spanned the years 1912 to 2006.

\section{References}

[1] Oral history interview with Philip Anderson, March 30, 1999; interviewer, Alexei Kojevnikov. http://www.aip.org/history-programs/niels-bohr-library/oral-histories/23362-1 (accessed Apr 12, 2019)

[2] Elizabeth Wood Presidential Memoir. "ACA 50th Anniversary: Presidential memoirs, Exhibitor memoirs, Nostalgia". https://www.amercrystalassn.org/h-beginnings_memoirs (accessed Apr 12, 2019) 